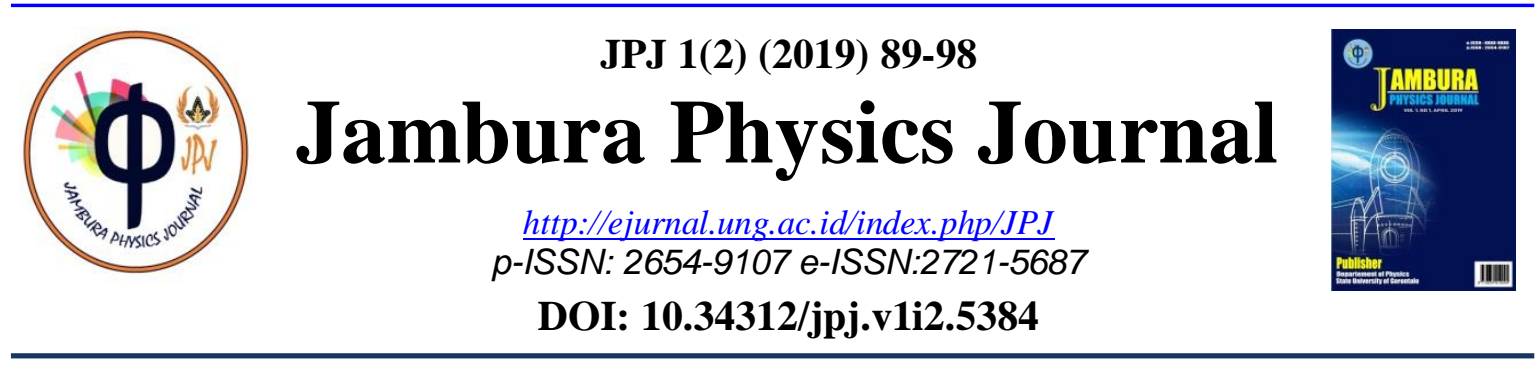

\title{
PENGARUH IMPLEMENTASI MODEL PHYSICS INDEPENDENT LEARNING (PIL) TERHADAP HASIL BELAJAR SISWA PADA PEMBELAJARAN FISIKA
}

\author{
Sunga I. ${ }^{1}$, Umar M.K. ${ }^{1}$, Ntobuo N.E. ${ }^{*}$ \\ ${ }^{1}$ Jurusan Universitas Negeri Gorontalo, Gorontalo
}

Accepted: September 2 2019. Approved: October 07 2019. Published: October 302019

\begin{abstract}
This study aims to determine the effect of the implementation of the Physics Independent Learning (PIL) model by looking at differences in student learning outcomes taught using the Physics Independent Learning (PIL) model and student learning outcomes taught using the Problem Based Learning model. This research was conducted at Gorontalo 3 Public High School in the 2018/2019 school year. The research method used was an experimental method with a pretest-posttest design control group design. Sampling was conducted using cluster random sampling techniques, class XI MIPA2 students as an experimental class who were taught using physics independent learning models and class XI MIPA3 students as a control class that was taught using a model of problem based learning. The instrument used was a test of learning outcomes in the form of objective questions. Test instrument data were analyzed using statistical analysis, namely the t-test. based on the results of calculations using the t-test at the level $(\alpha)=0.05$, tcount $=6.05>$ ttable $=1.68$ so that the hypothesis (H0) is rejected and the alternative hypothesis (H1) is accepted. Then it can be concluded that there is an effect of the implementation of the Physics Independent Learning (PIL) model on student learning outcomes, seen from differences in student learning outcomes that are taught using physics independent learning models with student learning outcomes that are taught using problem based learning models.
\end{abstract}

Keywords: Physics Independent Leaning; Learning Outcomes.

\section{PENDAHULUAN}

Perkembangan globalisasi sekarang ini menuntut setiap individu untuk selalu berinovasi dan meningkatkan kualitas diri dalam menghadapi tantangan-tantangan yang bermunculan, bukan hanya untuk mensejahterakan diri sendiri, namun peningkatan kualitas diri juga ikut menjadi sumbangsi untuk kemajuan suatu bangsa. Salah satu sarana

*Alamat Korespondensi

E-mail: : novantobuo@ung.ac.id

Jambura Physics Journal, Vol. 1 No. 2, Oktober 2019 
yang sangat menunjang untuk meningkatkan kualitas diri ada di bidang pendidikan, karena dengan pendidikan maka karakter dan kemampuan diri individu dapat dikembangkan. Sehingga dalam dunia pendidikan perlu diadakan peningkatan dan inovasi-inovasi yang kreatif. Lembaga yang dapat memfasilitasi semua itu adalah sekolah. Sekolah adalah tempat kedua menimbah ilmu setelah kedua orang tua. Sekolah memiliku peran menghasilkan sumber daya manusi yang memiliki kemampuan dan berdaya saing dengan adanya didikan dari para guru dalam proses pembelajarannya.

Belajar diartikan dalam arti yang luas, meliputi keseluruhan proses perubahan pada individu. Perubahan itu meliputi keseluruhan topic kepribadian, intelek maupun sikap, baik yang tampak maupun tidak. Oleh karena itu tidaklah tepat kalau belajar itu diartikan sebagai "ungkapan atau membaca pelajaran" maupun menyimpulkan pengetahuan atau informasi. Selain dari itu, belajar juga tidak dapat diartikan sebagai terjadinya perubahan dalam diri individu sebagai akibat dari kematangan, pertumbungan, atau insting

Fisika adalah mata pelajaran yang dapat mengembangan pengetahuan, sikap, dan nilai-nilai yang ada dalam kehidupan. Sehingga tenaga pengajar dituntut harus dapat menyajikan pembelajaran dalam bentuk yang sekreatif mungkin agar siswa dapat tertarik dan lebih mudah memahami pembelajaran fisika.

Dalam pengembangannya pembelajaran fisika perlu adanya inovasi, dengan menerapkan berbagai model pembelajaran, metode pembelajaran, dan strategi pembelajaran yang sesuai sehingga diharapkan penerapannya dapat dirasakan oleh peserta didik, agar peserta didik dapat secara aktif mengikuti pembelajaran, dan pembelajaran dapat menjadi kondusif di dalam kelas.

Pendekatan yang dilakukan melalui model pembelajaran Physics Independent Learning (PIL) untuk mempengaruhi keterampilan siswa dalam memecahkan masalah dan keterampilan siswa dalam belajar mandiri, sehingga siswa dapat belajar tidak hanya dari satu sumber belajar atau tidak hanya saat ada guru di kelas, tetapi siswa juga dapat belajar sendiri tanpa harus ada guru dengan beberapa sumber belajar di luar dari bahan ajar atau buku yang diberikan guru dalam proses pembelajaran dalam kelas. Sehingganya hasil belajar yang nantinya diperoleh oleh siswa dapat meningkat dan memenuhi standar kompetensi lulusan yang diterapkan sesuai kurikulum yang ada.

dalam sistem pendidikan nasional rumusan tujuan pendidikan, baik tujuan kurikuler maupun tujuan instruksional, menggunakan klasifikasi hasil belajar dari Benyamin Bloom yang secara garis besar membaginya menjadi tiga ranah, yaitu ranah kognitif,ranah afektif, dan ranah psikomotorik. Ranah kognitif meliputi beberapa tipe hasil belajar yang terdiri 
dari beberapa tingkatan yaitu: C1) Pengetahuan/knowledge menekannkan pada proses mental dalam mengingat dan mengungkapkan kembali informasi-informasi yang telah siswa peroleh sebelumnya,C2) Pemahaman/ comprehension berhubungan dengan penguasaan atau mengerti tentang sesuatu, C3) Aplikasi/application kemampuan kognisi yang mengharapkan siswa mampu mendemostrasikan pemahaman mereka dengan sebuah abstraksisesuatu melalui penggunaanya secara tepat ketika siswa dimita untuk itu, C4) Analisis / analysis menguraikan materi ke dalam bagian-bagiannya dan menentukan bagaimana bagian-bagian tersebut satu sama lain, C5) Sintesis/synthesis kemampuan untuk mengkombinasikan elemen-elemen untuk membentuk sebuah struktur yang unik atau system, dan C6) Evaluasi / evaluation kegiatan membuat penilaian berkenaan dengan nilai sebuah ide, kreasi cara, atau metode

Hasil belajar merupakan hasil daripenguasaan ilmu pengetahuan yang diuangkapkan dalam bentuk perubahan perilaku yang harus dicapai oleh siswa selama belajar di sekolah, menyangkut aspek kognitif yang berarti penguasaan materi pelajaran yang telah diberikan guru di kelas, yang di ukur dengan menggunakan alat test. Untuk mendapatkan hasil belajar yang mencapai KKM maka diperlukan pengembangan model pembelajaran yang digunakan di dalam kelas, sehingga siswa akan lebih semangat dan termotivasi dalam mengikuti proses pembelajaran dan dapat mengambil tanggung jawab dengan berperan aktif dalam kelas.

Salah satu pengembangan model pembelajaran adalah Independent Learning atau pembelajaran mandiri adalah sebuah proses sebagaimana proses lainnya, pola belajar ini mengikuti beberapa prosedur untuk bisa mencapai suatu tujuan. Proses belajar mandiri adalah suatu metode yang melibatkan siswa dalam tindakan-tindakan yang meliputi beberapa langkah, dan menghasilkan baik hasil yang tampak maupun yang tidak tampak. pengembangan model PILmenggunakanpendekatan saintifik dengan metode penyelidikan, penugasan, kolaborasi, diskusi, dan presentasi sehingga dapat menjembatani kesenjangan antara harapan kompetensi lulusan dengan keadaan di lapangan sesuai tuntutan abad 21.

Adapun tujuan dari penelitian ini adalah mengetahui pengaruh pada pembelajaran sebelum dan sesudah dibelajarkan model pembelajaran (PIL) terhadap hasil belajar siswa.

Secara oprasional tujuan yang dapat disajikan adalah untuk mengetahui perbedaan hasil belajar siswa yang dibelajarkan menggunakan model PIL dan hasil belajar siswa yang dibelajarkan menggunakan model pembelajara Problem Based Learning (PBL)? 


\section{METODOLOGI PENELITIAN}

Penelitian ini dilaksanakan di SMA N 3Gorontalo yang berlokasi di Jln. Achmad Nadjamuddin No.43, Kel Limba U Dua, Kec. Kota Selatan, Kota Gorontalo. Penelitian ini dilaksanakan pada semester genap tahun ajaran 2018/2019 pada bulan Maret-April.

Jenis penelitian ini adalah eksperimen. Penelitiaan eksperimen merupakan penelitian yang dimaksudkan untuk mengetahui ada tidaknya akibat dari "sesuatu" yang dikenakan pada subjek selidik. Caranya adalah dengan satu atau lebih kelompok eksperimen yang diberi perlakuan dengan satu atau lebih kelompok pembanding yang tidak menerima perlakuan. Instrumen yang digunakan dalam penelitian ini yaitu lembar validasi, dan tes hasil belajar kognitif siswa.

Uji kevalidan instrumentdigunakan rumus Korelasi Product Moment:

$$
r_{x y}=\frac{n(\Sigma X Y)-\left(\sum X\right)(\Sigma Y)}{\left.\left\{\left(n \sum X^{2}\right)-\left(\sum X\right)^{2}\right\}\left(n \sum Y^{2}\right)-(\Sigma Y)^{2}\right\}}
$$

Uji ketepatan suatu tes atau uji reliabilitas digunakan rumus Alpha Cronbach:

$$
r_{11}=\left(\frac{k}{k-1}\right)\left(1-\frac{\sum \sigma_{b}^{2}}{\sigma_{t}^{2}}\right)
$$

Analisis hasil belajar siswa dianalisis dengan beberapa uji, Uji normalitas data hasil penelitian digunakan pengujian statistik uji Liliefors, dengan kriteria pengujian terima $\mathrm{H}_{0}$ atau populasi berdistribusi normal apabila nilai $\mathrm{L}_{\text {hitung }} \leq \mathrm{L}_{\text {tabel }}$ pada $\alpha=0,05$.

Uji homogenitas data hasil penelitian digunakan pengujian statistik uji barlet:

$$
x^{2}=(\ln 10)\left\{B-\sum(n-1) \log s^{2}\right\}
$$

Uji hipotesis hasil penelitian digunakan pengujian statistik uji t:

$$
t_{\text {hitung }}=\frac{x_{1}-x_{2}}{\sqrt{\frac{s_{1}^{2}}{n_{1}}}+\frac{s_{2}^{2}}{n_{2}}}
$$

\section{HASIL PENELITIAN DAN PEMBAHASAN}

\section{Validitas Perangkat Pembelajaran}

Penelitian ini merupakan jenis penelitian eksperimen untuk melihat pengaruh implementsi model pembelajaran Physics Independen Learning (PIL) terhadap hasil belajar siswa pada pembelajaran fifika materi gelombang bunyi dengan menggunakan 
perangkat pembelajaran dan instrument yang telah di validasi oleh 3 validator yaitu dosen yang berada di jurusan Fisika Fakultas Matematika dan Ilmu Pengetahuan Alam Universitas Negeri Gorontalo. Hasil validasi perangkat pembelajaran dan instrument yang siap untuk dipakai. Validasi ini dilakukan untuk menyempurnakan perangkat pembelajaran dan instrument yang telah dibuat peneliti berdasarkan saran-saran dari validator.

Dari hasil validasi ahli oleh 3 orang validator menyatakan bahwa instrument yang terdiri dari silabus, RPP, bahan ajar, LKPD, dan tes hasil belajar layak digunakan dengan revisi keci. Untuk istrumen test setelah dinyatakan valid oleh dosen ahli kemudian peneliti melakukan uji dengan rumus Korelasi Product Moment:

Tabel 1 Hasil Validitas Test

\begin{tabular}{cccc}
\hline Butir Soal & $\mathrm{r}_{\text {hitung }}$ & Nilai & Status \\
\hline 1. & 0,3718 & 0,344 & Valid \\
2. & 0,6231 & 0,344 & Valid \\
3. & 0,7922 & 0,344 & Valid \\
4. & 0,4471 & 0,344 & Valid \\
5. & 0,4245 & 0,344 & Valid \\
6. & 0,5972 & 0,344 & Valid \\
7. & 0,8121 & 0,344 & Valid \\
8. & 0,8121 & 0,344 & Valid \\
9. & 0,524 & 0,344 & Valid \\
10 & 0,0858 & 0,344 & Tidak valid \\
11. & 0,4698 & 0,344 & Valid \\
12. & 0,1657 & 0,344 & Tidak valid \\
13. & 0,6295 & 0,344 & Valid \\
14. & 0,4845 & 0,344 & Valid \\
\hline
\end{tabular}

\section{Implementasi Model Physics Independent Learning (PIL)}

Pertemuan pertama dilaksanakan pada hari Senin tanggal 18 maret 2019, Pertemuan kedua dilaksanakan pada hari sabtu tanggal 23 maret 2019, Pertemuan ketiga dilaksananakan hari senin tanggal 25 maret 2019 dengan mengacu pada rencana pelaksanaan pembelajar (RPP) yang disusun sesuai sintaks dari model physics independent learning. yang terdiri dari 6 fase, yaitu inisiasi dan persistensi, fase 2 tanggung jawab, fase 3 penyelidikan mandiri dan kelompok, fase 4 analisis dan kolaborai, fase 5 presentasi dan diskusi, dan fase 6 penguatan dan evaluasi. 


\section{Implementasi Model Problem Based Learning (PBL)}

Pertemuan pertama dilaksanakan pada hari Rabu tanggal 13 maret 2019, Pertemuan kedua dilaksanakan pada hari selasa tanggal 19 maret 2019, Pertemuan ketiga dilaksananakan hari rabu tanggal 20 maret 2019 dengan mengacu pada rencana pelaksanaan pembelajar (RPP) yang disusun sesuai sintaks dari model problem based learning. yang terdiri dari 5 fase, yaitu orientasi siswa pada masalah, fase 2 mengorientasikan siswa untuk belajar, fase 3 membimbing penyelidikan individu dan kelompok, fase 4 mengembangkan dan menyajikan hasil karya, fase 5 menganalisis dan mengevaluasi proses pemecahan masalah.

\section{Deskripsi Hasil Penelitian}

Data hasil belajar siswa yang dianalisis dalam penelitian ini terdiri dari dua kelompok yaitu kelas eksperimen yaitu kelompok siswa yang dibelajarkan menggunakan model pembelajaran Physics Independent Learnig dan kelas control yaitu kelompok siswa yang dibel $r^{*}$.

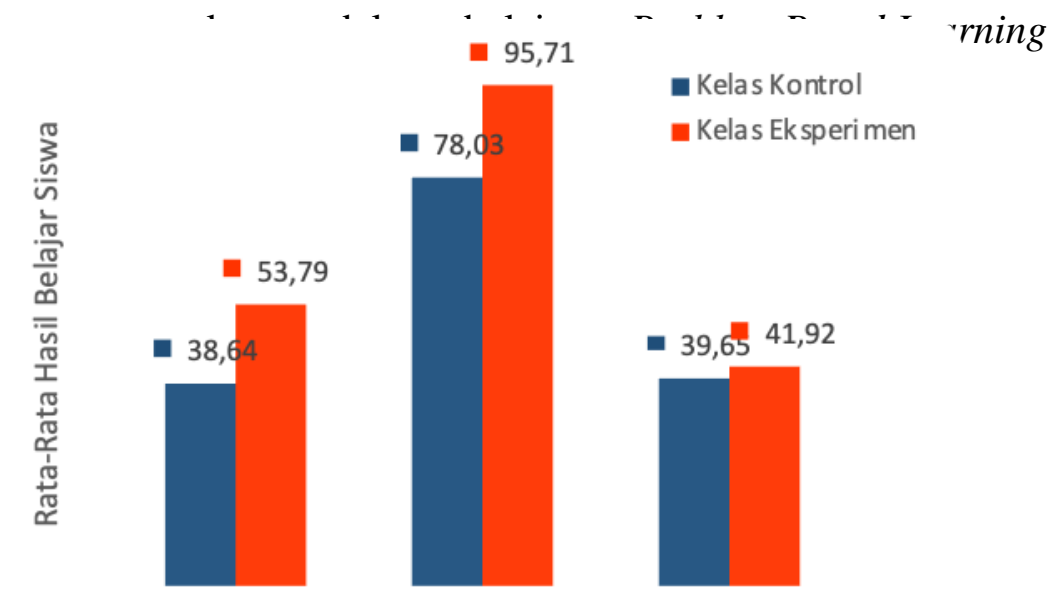

Gambar 1. Rata-rata hasil belajar siswa

Hasil rata-rata pre-test dan post-test antara kelas eksperimen dan kelas kontrol nilainya berbeda, sehingga dapat disimpulkan bahwa perolehan skor rata-rata pre-test dan post-test untuk kelas eksperimen yang dibelajarkan menggunakan model pembelajaran Physics Independent Learning lebih tinggi dibandingkan dengan perolehan skor rata-rata pre-test dan post-test untuk kelas kontrol yang dibelajarkan menggunakan model pembelajaran Problem Based Learning. Kemajuan hasil belajar siswa kelas eksperimen lebih meningkat dibandingkan kelas kontrol yaitu rata-rata kemajuan hasil belajar siswa kelas eksperimen 41,92 sedangkan rata-rata kemajuan hasil belajar siswa kelas kontrol 39,65 


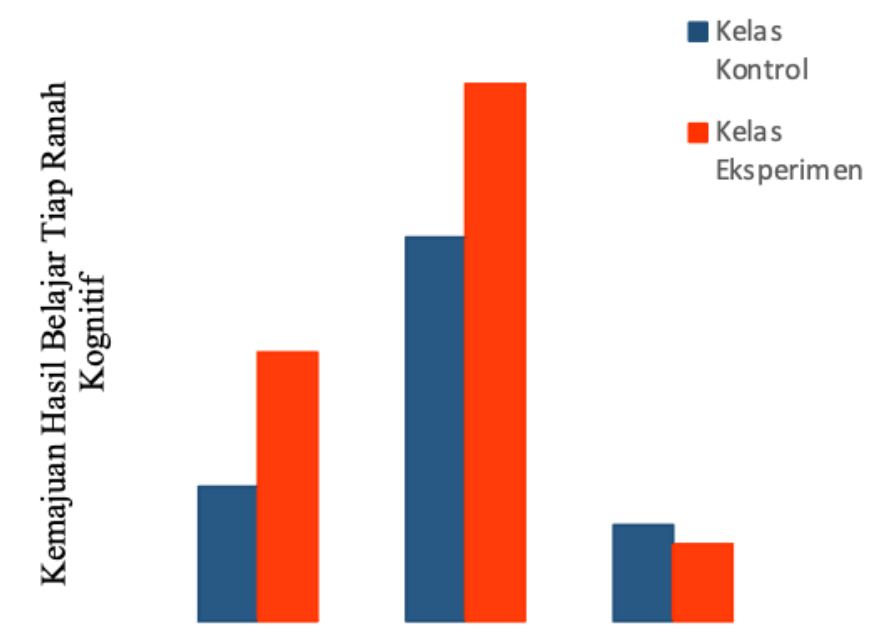

Gambar 2. Kemajuan hasil belajar tiap ranah kognitif

Secara umum kelas eksperimen mengalami kemajuan hasil belajar lebih besar dibandingkan kelas kontrol. Pada aspek memahami (C2), dan aspek mengaplikasikan (C3) kelas eksperimen memperoleh rata-rata skor kemajuan hasil belajar lebih besar dibandingkan kelas control, akan tetapi pada aspek menganalisis (C4) kelas control memperoleh rata-rata skor kemajuan hasil belajar lebih besar daripada kelas eksperimen

\section{Uji Normalitas Data}

Pengujiannormalitas data bertujuan untuk mengetahui apakah data terdistribusi normal atau tidak. Berikut diberikan data hasil ujicoba normalitas data.

Tabel 2. Hasil Uji Normalitas Data

\begin{tabular}{ccccc}
\hline Kelas & Jenis Test & $X^{2}$ hitung & $X^{2}$ tabel & Keterangan \\
\hline Eksperimen & Pre-Test & 0,130 & 0,154 & Normal \\
& Post-Test & 0,133 & 0,154 & \\
\multirow{2}{*}{ Kontrol } & Pre-Test & 0,143 & 0,154 & Normal \\
& Post-Test & 0,101 & 0,154 & \\
& & &
\end{tabular}

Untuk kedua kelas, kelas eksperimen dan kelas kontrol keduanya memiliki $X^{2}$ hitung $<X^{2}$ tabel, maka data hasil penelitian untuk kelas eksperimen maupun kelas kontrol berasal dari populasi yang terdistribusi normal, maka penyebaran data di kedua kelas juga terdistribusi normal.

\section{Uji Homogenitas Data}

Hasil perhitungan diperoleh $X^{2}$ hitung sebesar 9,2. pada taraf nyata $\alpha=0,05$ diperoleh $X^{2}$ tabel sebesar 11,07. Hasil perhitungan ini artinya varians data popilasi 
tergolong homogen. Dengan demikian persyaratan Uji t dua sampel independent telah terpenuhi sehingga dapat digunakan untuk menguji hipotesis penelitian

\section{Pengujian Hipotesis}

Data dinyatakan terdistribusi normal dan homogen, maka setelah itu untuk menguji hipotesis digunakan rumus uji-t. pengujian hipotesis pada penelitian ini dilakukan bertujuan untuk mengetahui apakah terdapat perbedaan hasil belajar siswa yang dibelajarkan menggunakan model Physics Independent Learning pada kelas eksperimen dengan hasil belajar siswa yang dibelajarkan menggunakan model Problem Based Learning pada kelas kontrol.

Hasil perhitungan dengan menggunakan uji t dua sampel independent diperoleh $\mathrm{t}_{\text {hitung }}=6,38$ dan $\mathrm{t}_{\text {tabel }}=1,68$ pada taraf 0,05 dengan $d k=64$. Hal ini menunjukan bahwa nilai $t_{\text {hitung }}=6,38>\mathrm{t}_{\text {tabel }}=1,68$ yang berarti $\mathrm{H}_{0}$ ditolak dan $\mathrm{H}_{1}$ diterima. Sesuai dengan uji statistik bahwa terdapat perbedaan antara hasil belajar siswa yang dibelajarkan menggunakan model Physics Independent Learning terhadap hasil belajar siswa yang dibelajarkan menggunakan model PBL.

Melihat nilai kemajuan rata-rata siswa pada ranah kognitif setelah diberikan perlakuan maka dapat dikatakan bahwa pembelajaran dengan menggunakan model physics independent learning mampu meningkatkan hasil belajar siswa, dapat dilihat pada Gambar 2, hal ini karena pada kelas eksperimen siswa diberikan kesempatan dan dituntut agar dapat merumuskan masalah dan hipotesis secara individu bukan kelompok, sedangkan pada kelas kontrol perumusan masalah dan hipotesis dilakukang secara berkelompok, hal ini juga sesuai dengan teori yang dikemukakan oleh hal ini sesuai dengan teori Heller \& Heller, (2010) Model PIL merupakan model pembelajaran sains inovatif yang dapat mendorong setiap individu memecahkan masalah dan mengajarkan tahapan pemecahan masalah untuk berpikir kritis dan memiliki kemandirian. Teori yang dikemukakan juga oleh Johnson (3003 : 171) yang menjelaskan bahwa physics independen learning adalah proses belajar mandiri yang melibatkan siswa dalam pembelajaran dimana siswa berperan aktif dalam pengalaman belajar mereka baik pada mereka sendiri ataupun bekerja sama dengan teman sebaya, sehingga dalam pembelajarajn siswa yang dibelajarkan dapat bertanggung jawab dengan dirinya sendiri sehingga timbul dalam diri siswa untuk berperan aktif dalam pembelajaran, jika siswa sudah dapat bertanggung jawab dengan dirinya sendiri maka secara tidak langsung kemauan belajar dalam dirinya meningkat dan berdampak pada hasil belajarnya juga yang meningkat. 
Model physics independent learning berkaitan erat dengan model PBL karena model PIL merupakan analisis dari model PBL dan CL yang dimodifikasi sehingga langkah-langkah pembelajaran pada model PIL itu sejalan dengan langkah-langah pembelajaran pada model PBL, hal ini sejalan denga teori Pandiangan, dkk (2017:3) Kelemahan-kelemahan yang ada pada model PBL dan model CL dapat diatasi dengan mengembangkan model alternatif yang diduga dapat meningkatkan keterampilan pemecahan masalah dan keterampilan belajar mandiri siswa. Model pembelajaran yang cocok dikembangkan untuk meningkatkan keterampilan pemecahan masalah dan keterampilan belajar mandiri siswa adalah model PIL yang sesuai karakteristik pembelajaran orang dewasa dan merupakan analisis dari model PBL dan model CL dengan sejumlah modifikasi sehingga dapat diterapkan pada semua mahasiswa yang berasal dari beragam kemampuan akademik, budaya, dan jenjang umur. namun pada model PIL ada satu fase yang tidak ada pada model PBL yaitu fase tanggung jawab. Model PIL lebih ditekankan pada fase tanggung jawab ini karena fase ini yang akan membentuk karakter siswa untuk lebih meningkatkan kemampuan dirinya dalam pembelajaran sehingga dapat meningkatkan hasil belajaran yang akan didapat nantinya, pada model PBL juga ada tanggung jawab namun tanggung jawab pada model PBL tidak di atur atau diarahkan di sintaks sehingga tidak menjadi suatu penekanan dalam model PBL. Berdasarkan uraian diatas dapat disimpulkan bahwa dengan menggunakan model physics independent learnng dapat meningkatkan hasil belajar siswa dibandingkan dengan menggunakan model problem based learning.

\section{KESIMPULAN}

Berdasarkan hasil penelitian dan pembahasan yang telah dilakukan maka dapat disimpimpulkan bahwa, terdapat pengaruh implementasi model PIL terhadap hasil belajar siswa, terlihat dari perbedaan hasil belajar siswa yang dibelajarkan menggunakan model pembelajaran PIL dengan hasil belajar siswa yang dibelajarkan menggunakan model pembelajaran problem based learning. Hal ini dapat dilihat berdasarkan hasil analisis data pada pengujian hipotesis, dimana nilai thitung $=6,38$ sedangkan ttabel pada taraf nyata $(\alpha$ $=0,05)=1,68$ yang berarti $\mathrm{H} 0$ ditolak atau $\mathrm{H} 1$ diterima. Hal lain dapat dilihat yaitu dari skor rata-rata hasil belajar siswa pada kelas eksperimen dan kelas kontrol. Untuk kelas eksperimen skor rata-rata lebih tinggi yaitu 95,71 sedangkan untuk kelas kotrol skor ratarata hasil belajar siswa yaitu 78,03 . 


\section{REFERENSI}

Arikunto, Suharsimi. 2010. Prosedur Penelitian Suatu Pendekatan Praktik Edisi Revisi. Jakarta: Rineka Cipta

Arikunto, Suharsimi. 2013. Manajemen Penelitian. Jakarta: Rineka Cipta

Hanief, Yulingga Nanda dan Wasis Himawanto. 2017. Statistik Pendidikan. Yogyakarta: CV Budi Utama

Johnson, B. Elaine. 2002. Contextual Teaching and Learning. Makassar: Mizan Media Utama

Pandiangan, dkk. 2017.Buku Model Physics Independent Learning, Surabaya: Juadar Press

Suardi, Moh. 2018. Belajar Dan Pembelajaran. Yogyakarta: Deepublis

Sinar. 2018. Metode Active Learning Upaya Peningkatan Keaktifan dan Hasil Belajar Siswa. Yogyakarta: Deepublish (Grup penerbitan CV. Budi Utama)

Sudjana, nana. 2009. Penilaian hasil proses belajar mengajar. Bandung: PT Remaja Rosdakarya

Sudjana, Nana. 2005. Penilaian Hasil Proses Belajar Mengajar. Bandung: PT Remaja Rosdakarya

Supardi. 2016. Penilaian Autentik. Jakarta: Raja Grafindo Persada 